\title{
Observations of core ion cyclotron emission on ASDEX Upgrade tokamak
}

Ochoukov, R.; Bobkov, V.; Chapman, B.; Dendy, R.; Dunne, M.; Faugel, H.; García-Muñoz, M.; Geiger, B.; Hennequin, P.; McClements, K.G.

Total number of authors:

16

Published in:

Review of Scientific Instruments

Link to article, DOI:

$10.1063 / 1.5035180$

Publication date:

2018

Document Version

Publisher's PDF, also known as Version of record

Link back to DTU Orbit

Citation $(A P A)$ :

Ochoukov, R., Bobkov, V., Chapman, B., Dendy, R., Dunne, M., Faugel, H., García-Muñoz, M., Geiger, B. Hennequin, P., McClements, K. G., Moseev, D., Nielsen, S., Rasmussen, A. N., Schneider, P., Weiland, M., \& Noterdaeme, J-M. (2018). Observations of core ion cyclotron emission on ASDEX Upgrade tokamak. Review of Scientific Instruments, 89(10), [10J101]. https://doi.org/10.1063/1.5035180

\section{General rights}

Copyright and moral rights for the publications made accessible in the public portal are retained by the authors and/or other copyright owners and it is a condition of accessing publications that users recognise and abide by the legal requirements associated with these rights.

- Users may download and print one copy of any publication from the public portal for the purpose of private study or research.

- You may not further distribute the material or use it for any profit-making activity or commercial gain

- You may freely distribute the URL identifying the publication in the public portal 


\section{Observations of core ion cyclotron emission on ASDEX Upgrade tokamak}

R. Ochoukov, V. Bobkov, B. Chapman, R. Dendy, M. Dunne, H. Faugel, M. García-Muñoz, B. Geiger, P. Hennequin, K. G. McClements, D. Moseev, S. Nielsen, J. Rasmussen, P. Schneider, M. Weiland, J.-M. Noterdaeme, ASDEX Upgrade Team, and EUROfusion MST1 Team

Citation: Review of Scientific Instruments 89, 10J101 (2018); doi: 10.1063/1.5035180

View online: https://doi.org/10.1063/1.5035180

View Table of Contents: http://aip.scitation.org/toc/rsi/89/10

Published by the American Institute of Physics

\section{Articles you may be interested in}

Radio frequency measurements of energetic-particle-driven emission using the ion cyclotron emission diagnostic on the DIII-D tokamak

Review of Scientific Instruments 89, 101102 (2018); 10.1063/1.5035561

Dynamic neutral beam current and voltage control to improve beam efficacy in tokamaks

Physics of Plasmas 25, 056109 (2018); 10.1063/1.5016160

Synthetic diagnostic for assessing spatial averaging of charge exchange recombination spectroscopy measurements

Review of Scientific Instruments 89, 10D101 (2018); 10.1063/1.5036964

Multi-scale transport in the DIII-D ITER baseline scenario with direct electron heating and projection to ITER

Physics of Plasmas 25, 022509 (2018); 10.1063/1.5011387

Physics of increased edge electron temperature and density turbulence during ELM-free QH-mode operation on DIII-D

Physics of Plasmas 25, 055904 (2018); 10.1063/1.5017964

Core radial electric field and transport in Wendelstein 7-X plasmas

Physics of Plasmas 25, 022508 (2018); 10.1063/1.4999842

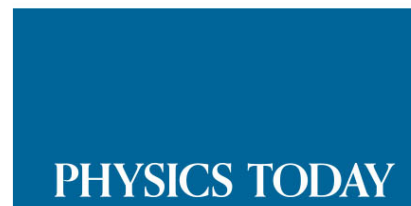

MANAGER'S GUIDE

WHITEPAPERS
Accelerate R\&D with

Multiphysics Simulation
READ NOW

PRESENTED BY

๑ $\subset$ OMSOL 


\title{
Observations of core ion cyclotron emission on ASDEX Upgrade tokamak
}

\author{
R. Ochoukov, ${ }^{1, a)}$ V. Bobkov, ${ }^{1}$ B. Chapman, ${ }^{2}$ R. Dendy, ${ }^{2,3}$ M. Dunne, ${ }^{1}$ H. Faugel, ${ }^{1}$ \\ M. García-Muñoz, ${ }^{4}$ B. Geiger, ${ }^{1}$ P. Hennequin, ${ }^{5}$ K. G. McClements, ${ }^{3}$ D. Moseev, ${ }^{6}$ \\ S. Nielsen, ${ }^{7}$ J. Rasmussen, ${ }^{7}$ P. Schneider, ${ }^{1}$ M. Weiland,${ }^{1}$ J.-M. Noterdaeme,,${ }^{1,8}$ \\ ASDEX Upgrade Team, ${ }^{\text {b) }}$ and EUROfusion MST1 Team ${ }^{\mathrm{c}}$ ) \\ ${ }^{1}$ Max Planck Institute for Plasma Physics, Boltzmannstr. 2, D-85748 Garching, Germany \\ ${ }^{2}$ Centre for Fusion, Space and Astrophysics, University of Warwick, Coventry CV4 7AL, United Kingdom \\ ${ }^{3}$ CCFE, Culham Science Center, Abingdon, Oxfordshire OX14 3DB, United Kingdom \\ ${ }^{4}$ FAMN Department, Faculty of Physics, University of Seville, 41012 Seville, Spain \\ ${ }^{5}$ Laboratoire de Physique des Plasmas, Ecole Polytechnique, 91128 Palaiseau, France \\ ${ }^{6}$ Max Planck Institute for Plasma Physics, Wendelsteinstr. 1, 17491 Greifswald, Germany \\ ${ }^{7}$ Department of Physics, Technical University of Denmark, Fysikvej, b. 309, DK-2800 Kongens Lyngby, Denmark \\ ${ }^{8}$ Applied Physics Department, UGent, 9000 Gent, Belgium
}

(Presented 17 April 2018; received 13 April 2018; accepted 30 May 2018; published online 6 July 2018)

\begin{abstract}
The B-dot probe diagnostic suite on the ASDEX Upgrade tokamak has recently been upgraded with a new $125 \mathrm{MHz}, 14$ bit resolution digitizer to study ion cyclotron emission (ICE). While classic edge emission from the low field side plasma is often observed, we also measure waves originating from the core with fast fusion protons or beam injected deuterons being a possible emission driver. Comparing the measured frequency values with ion cyclotron harmonics present in the plasma places the origin of this emission on the magnetic axis, with the fundamental hydrogen/second deuterium cyclotron harmonic matching the observed values. The actual values range from $\sim 27 \mathrm{MHz}$ at the on-axis toroidal field $\mathrm{B}_{\mathrm{T}}=-1.79 \mathrm{~T}$ to $\sim 40 \mathrm{MHz}$ at $\mathrm{B}_{\mathrm{T}}=-2.62 \mathrm{~T}$. When the magnetic axis position evolves during this emission, the measured frequency values track the changes in the estimated on-axis cyclotron frequency values. Core ICE is usually a transient event lasting $\sim 100 \mathrm{~ms}$ during the neutral beam startup phase. However, in some cases, core emission occurs in steadystate plasmas and lasts for longer than $1 \mathrm{~s}$. These observations suggest an attractive possibility of using a non-perturbing ICE-based diagnostic to passively monitor fusion alpha particles at the location of their birth in the plasma core, in deuterium-tritium burning devices such as ITER and DEMO. https://doi.org/10.1063/1.5035180
\end{abstract}

\section{INTRODUCTION}

The purpose of this paper is to present novel detailed observations of ion cyclotron emission (ICE) originating from the plasma core region in ASDEX Upgrade (AUG) plasmas. Frequency matching between the measured value and the cyclotron frequency $\left(\omega_{\mathrm{ci}}=\mathrm{q}_{\mathrm{i}} \mathrm{B} / \mathrm{m}_{\mathrm{i}}\right.$, where $\omega_{\mathrm{ci}}$ is the angular cyclotron frequency of the ion species $\mathrm{i}, \mathrm{q}_{\mathrm{i}}$ is the ion charge, $B$ is the magnitude of the local magnetic field, and $m_{i}$ is the ion mass) provides information on the likely source location of the emission and which ion species could be responsible for driving it. This technique places the origin of the observed ICE signal at the magnetic center of the plasma with either the fundamental minority proton or the second deuterium cyclotron harmonics (or both) exciting the emission. The possibility that this emission could be excited by fusion products at the location of their birth, in the plasma core, raises the intriguing possibility of using an ICE diagnostic as a passive

\footnotetext{
Note: Paper published as part of the Proceedings of the 22nd Topical Conference on High-Temperature Plasma Diagnostics, San Diego, California, April 2018.

a) Author to whom correspondence should be addressed: roman.ochoukov@ ipp.mpg.de

b) See the author list in H. Zohm et al., Nucl. Fusion 55, 104010 (2015).

c) See the author list in H. Meyer et al., Nucl. Fusion 57, 102014 (2017).
}

non-perturbing method to study fusion born alpha particles in D-T burning fusion reactors such as ITER and DEMO. Note that a similar case has been made previously by McClements et al., ${ }^{1}$ our paper strengthens their case with core ICE observations.

ICE is a frequently observed phenomenon in toroidal magnetized plasma devices such as tokamaks and stellarators. $^{2-8}$ The emission consists of radio frequency (RF) waves generated by a resonant interaction between fast ions and a plasma instability. The frequency of the emission is in the ion cyclotron range-of frequency (ICRF) band, typically 10$100 \mathrm{MHz}$ in conventional tokamaks. The sources of fast ions can be fusion reactions, neutral beam injections (NBIs), or acceleration by ICRF waves. The most likely instability type responsible for the emission is the magnetoacoustic cyclotron instability (MCI). ${ }^{9}$ ICE observations are not limited to a single type of toroidal confinement device. Examples of ICE in tokamaks include ASDEX Upgrade, ${ }^{2}$ JET, ${ }^{3}$ TFTR,${ }^{4}$ DIII-D, ${ }^{5}$ KSTAR, ${ }^{6}$ and JT-60U. ${ }^{7}$ An example of ICE observed on a stellarator is from LHD. ${ }^{8}$ Note that the presence of fast ions alone is not enough to generate ICE, the fast ion population must also be either non-monotonic (e.g., bump-on-tail) in energy ${ }^{10}$ or anisotropic in its velocity components, ${ }^{3}$ or both. Additionally, as ICE diagnostics are generally placed near or behind the 
first wall, the excited wave must be able to reach the detector without undergoing complete reabsorption/scattering.

"Classic" ICE, originating from the low field side plasma edge, is usually attributed to local non-monotonicity and anisotropy of the fast ion distribution function resulting from the large excursion orbits of certain fast ions from the core to the edge. ${ }^{3}$ However, core ICE excitation, driven by fast fusion products born in beam-target fusion reactions, could also occur if the fast ions are non-monotonic ${ }^{10}$ or anisotropic. The aim of our paper is to present detailed ICE measurements from ASDEX Upgrade that show emission taking place close to the magnetic axis, with fusion-born fast protons being a likely driver. These measurements have been obtained with a new ICE diagnostic, which is the subject of Sec. II.

\section{DIAGNOSTIC DESCRIPTION}

ICE is an electromagnetic wave, which consists of timevarying electric and magnetic field components. As a result, it is possible to detect the emission signal directly with an inductor, or a B-dot probe. ASDEX Upgrade is equipped with multiple in-torus B-dot probes. ${ }^{11}$ These are positioned on both the low- and the high-field sides (LFS and HFS) of the tokamak (Fig. 1). At each position shown in Fig. 1, there are two probes oriented perpendicular to each other, with the exception of the probe pair in Sector 11 (Fig. 1): these two probes are oriented parallel to each other to allow a phase/wavenumber measurement. Poloidally, the LFS probes are near the midplane and the HFS probes are $\sim 0.8 \mathrm{~m}$ above the midplane.

The signal outputs from all of the probe pairs are digitized with the so-called slow digitizers. ${ }^{11}$ The slow digitization scheme relies on rectifying an RF signal into a DC voltage via a logarithmic (log) RF detector. ${ }^{11}$ Each $\log$ detector contains

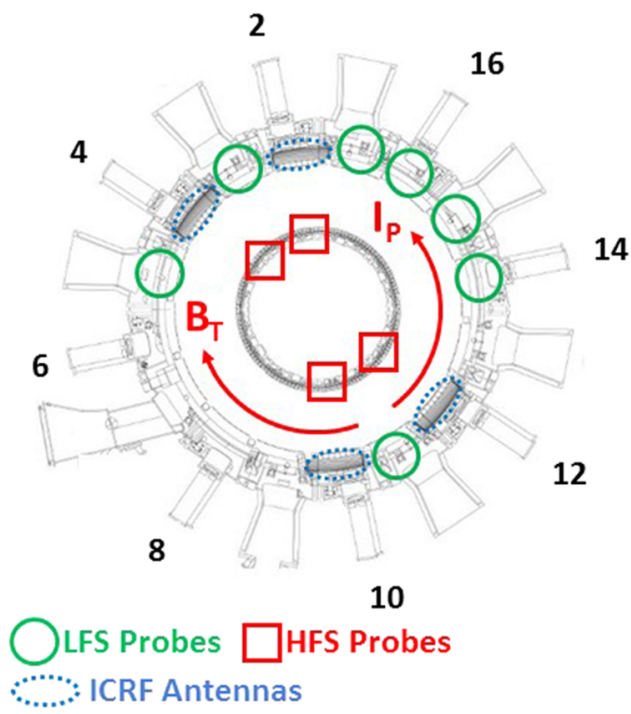

FIG. 1. A top cross-sectional view of the RF probe positions in ASDEX Upgrade. Shown are the low field side (LFS) probes, the high field side (HFS) probes, and the ICRF antennas. The standard direction of the plasma current $\mathrm{I}_{\mathrm{P}}(+)$ and the toroidal magnetic field $\mathrm{B}_{\mathrm{T}}(-)$ are shown. The numbers indicate the torus sector locations (only even numbers are shown). two RF inputs, which makes it possible to measure the phase between the inputs. The phase value is also output in the form of a DC voltage. ${ }^{11}$ Once rectified, the DC outputs of the $\log$ detectors are then digitized via a serial input/output-based system at $200 \mathrm{kHz}{ }^{11}$ To minimize the effects of low frequency plasma waves and high frequency harmonics on the output signal, the log detectors are equipped with a pair of bandpass filters - the RF signal is strongly attenuated below $10 \mathrm{MHz}$ and above $50 \mathrm{MHz}$ before it is rectified. ${ }^{11}$ The slow digitization scheme loses the information on the RF signal frequency. As a result, a different fast digitization scheme has been installed on AUG during the 2017 experimental campaign to obtain the ICRF and ICE frequency spectrum.

The RF signal from the Sector 11 probe pair (the pair with the two probes oriented parallel to each other; see Fig. 1) is divided via a $3 \mathrm{~dB}$ splitter-one half of the signal is routed to a slow digitizer and the other half is digitized by using the fast system. The fast digitization scheme consists of a 2-channel, $125 \mathrm{MHz}, 14$ bit digitizer. $^{12}$ The internal memory of the digitizer (500 MB) limits the data acquisition duration per plasma shot: the system samples the two RF signals during a $1 \mathrm{~ms}$ time window, every $10 \mathrm{~ms}$, for the duration of $8 \mathrm{~s}$, long enough for most AUG discharges. Due to a limited data storage space available, the fast system only operates when requested. The fast digitizer system is equipped with four notch filters, two are centered at $30.0 \mathrm{MHz}$ and two at $36.5 \mathrm{MHz}$, with $40 \mathrm{~dB}$ attenuation at the central frequency and with a $3.0 \mathrm{~dB}$ width of $1.4 \mathrm{MHz}$. The purpose of the notch filters is to remove the frequency component launched by ICRF antennas, in order to study ICE. The three modes of operation of the fast digitization scheme are (1) no filters applied; (2) with the $30 \mathrm{MHz}$ filters active; and (3) with the $36.5 \mathrm{MHz}$ filters active. The fast system is positioned inside the torus hall and can be accessed remotely via an Ethernet connection to control the state of the notch filters and retrieve the data. In Sec. III, we present ICE results obtained either in ICRF-free discharges or before ICRF-on phases, with the fast diagnostic operating in the "no filters applied" mode.

\section{EXPERIMENTAL RESULTS AND DISCUSSION}

To demonstrate the fast diagnostic capabilities, we first present a "classic" ICE example—low field side edge emission in the presence of neutral beam injected fast ions [Fig. 2(a)]. To avoid any ambiguity in the identification of the driving fast ion species, the discharge considered here has a hydrogen target plasma, heated with hydrogen beams (operated at $52 \mathrm{keV}$ and $72 \mathrm{keV}$ primary injection energies). The on-axis toroidal magnetic field $\left(\mathrm{B}_{\mathrm{T}}\right)$ is $-2.47 \mathrm{~T}$, and the plasma current is $0.8 \mathrm{MA}$. The discharge is in $\mathrm{H}$-mode, which is maintained by 4.5 MW of NBI and 2.7 MW of electron cyclotron resonance heating $(\mathrm{ECRH})$ power. A plasma triangularity scan is performed between $2 \mathrm{~s}$ and $3 \mathrm{~s}$ of the discharge, which changes the edge localized modes (ELMs) from a high- to a low-frequency type, while maintaining the heating power constant [Fig. 2(a)]. During this time the plasma stored energy increases [Fig. 2(b)], and after this increase an instability develops with a frequency of $\sim 30 \mathrm{MHz}$ [Figs. 2(c) and 2(d)]. Frequency matching with the fundamental hydrogen cyclotron frequency places the 


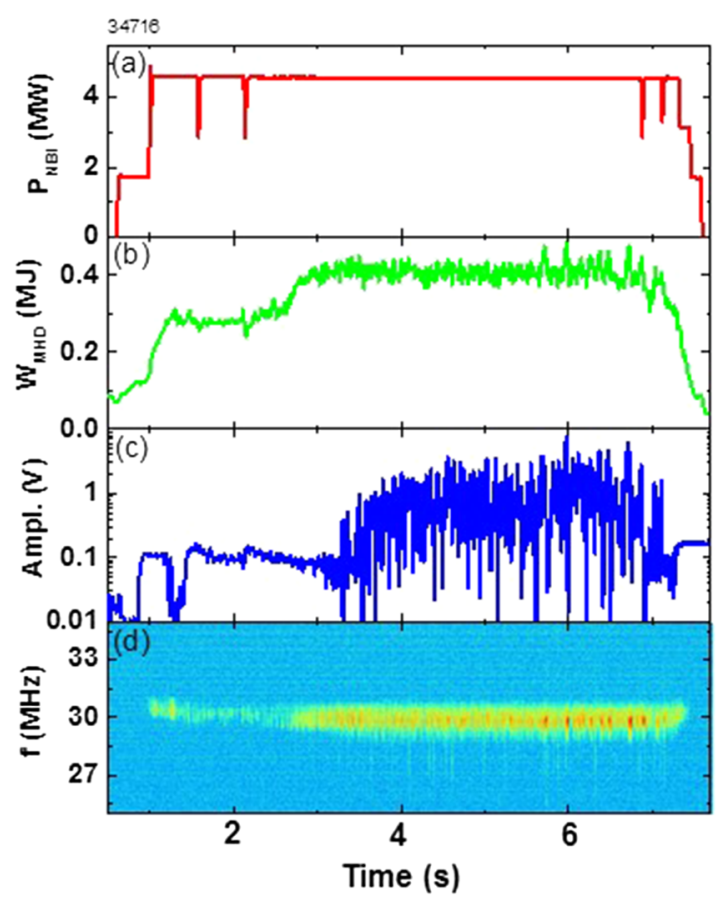

FIG. 2. A "classic" ICE example of low field side edge emission due to NBI fast ions on ASDEX Upgrade (discharge \#34716, $\mathrm{B}_{\mathrm{T}}=-2.47 \mathrm{~T}$, $\mathrm{H}$ plasma, $\mathrm{H}$ beams). The plotted quantities are (a) the NBI power $\mathrm{P}_{\mathrm{NBI}}$; (b) the stored plasma energy $\mathrm{W}_{\mathrm{MHD}}$; (c) the RF probe amplitude on the low field side, on a logarithmic scale; and (d) the measured ICE intensity frequency spectrum f, on a logarithmic scale [see (c) for relative scale].

origin of this emission at the low field side plasma boundary, at the same radial position as the plasma pedestal. Once the ICE has developed, the emission characteristics are often not constant in time but show periodic modulations that are correlated with the ELM crashes.

We occasionally observe on ASDEX Upgrade that deuterium plasmas heated with deuterium NBI power (operated at $60 \mathrm{keV}$ primary injection energy) generate ICE at frequencies that match the hydrogen cyclotron frequency/second deuterium cyclotron harmonics at the position of the magnetic axis, not the edge (Fig. 3). This emission type has been detected in both H-mode (Fig. 3) and L-mode plasmas on AUG. The observed frequency ranges from $\sim 27 \mathrm{MHz}$ at $\mathrm{B}_{\mathrm{T}}=-1.79 \mathrm{~T}$ to $\sim 37 \mathrm{MHz}$ at $\mathrm{B}_{\mathrm{T}}=-2.47 \mathrm{~T}$ (Fig. 3). For the case of the lower magnetic field $\mathrm{B}_{\mathrm{T}}=-1.79 \mathrm{~T}$, the second harmonics at $\sim 54 \mathrm{MHz}$ is also detected by using the fast digitizer (Fig. 4). This emission type usually appears during the first $100 \mathrm{~ms}$ of the NBI startup phase [Figs. 3(a)-3(d)], which is still long enough to be easily detected between the $10 \mathrm{~ms}$ acquisition windows of the fast diagnostic. Since the plasma pressure profile evolves during this time interval and shifts the radial position of the magnetic axis [Fig. 3(b)], the estimated on-axis hydrogen cyclotron frequency $\left(\mathrm{f}_{\Omega \mathrm{H}+}\right)$ also changes. The measured ICE frequency tracks this change of $f_{\Omega \mathrm{H}}$ [Fig. 3(d)]. The short duration of core ICE in discharges such as \#34552 is in line with the expectation that such phenomena are only likely to occur transiently, before the fast particles driving the emission quickly relax to form a slowing-down distribution that decreases monotonically with energy. ${ }^{10}$

However, we also observe cases in which a core instability occurs during a steady-state part of the discharge and persists for longer than $1 \mathrm{~s}$ [Figs. 3(e)-3(h)]. Although it is not clear what triggers the core ICE shown in Figs. 3(e)-3(h), the instability promptly disappears when the NBI source switches from a tangential to a more radial injection geometry (while
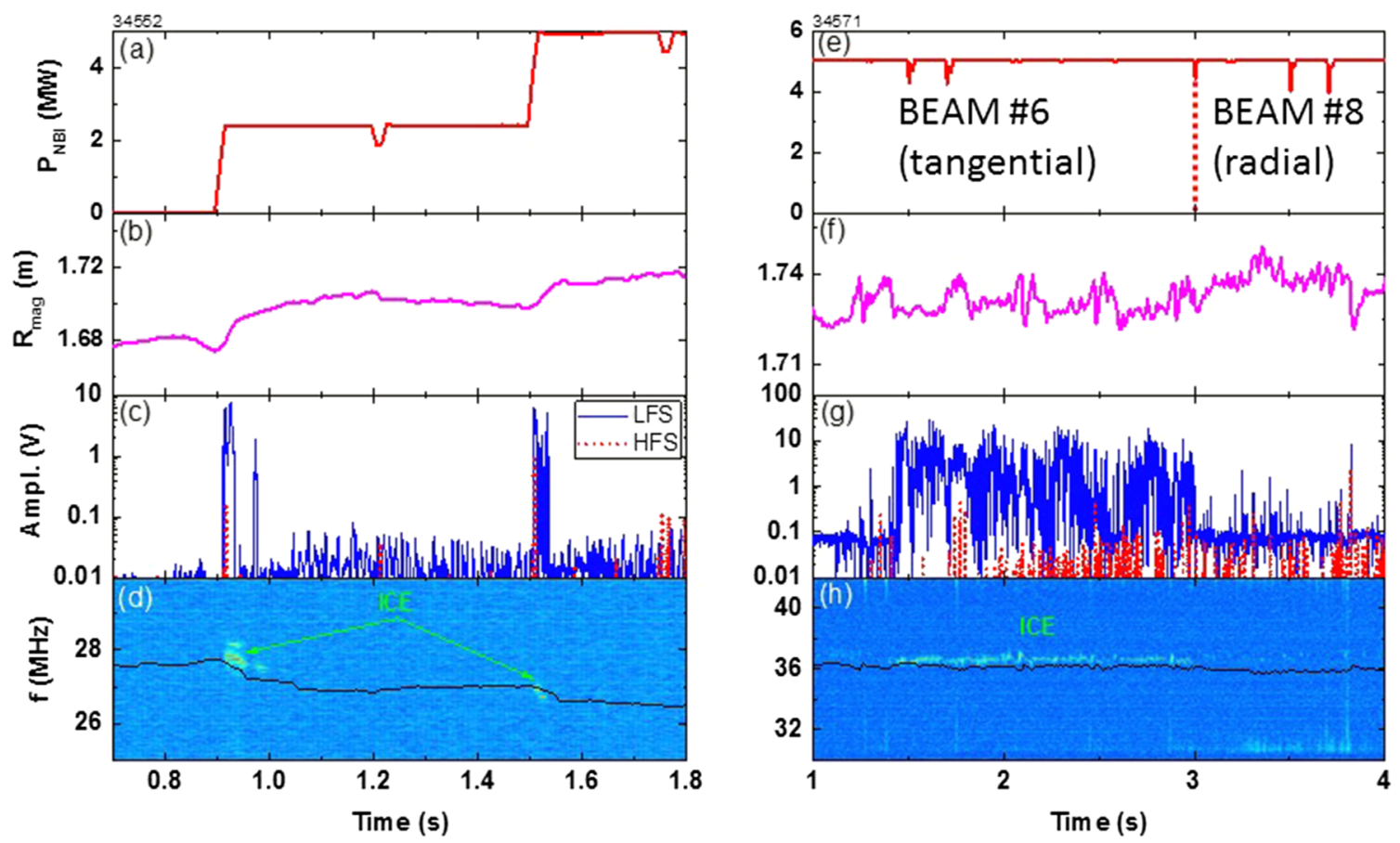

FIG. 3. Examples of core ICE at $\mathrm{B}_{\mathrm{T}}=-1.79 \mathrm{~T}$ [discharge \#34552, (a)-(d)] and $\mathrm{B}_{\mathrm{T}}=-2.47 \mathrm{~T}$ [discharge \#34571, (e)-(h)]. D plasma and D beams. The plotted quantities are the NBI power $\mathrm{P}_{\mathrm{NBI}}$ (a) and (e); the radial position of the magnetic axis $\mathrm{R}_{\operatorname{mag}}$ (b) and (f); the amplitude of the RF signal on the low and the high field sides (LFS and HFS), on a logarithmic scale (c) and (g); and the frequency spectra of measured ICE intensity, on a logarithmic scale (d) and (h) [see (c) and (g) for relative scales, respectively]. The black lines in (d) and (h) indicate the fundamental hydrogen cyclotron frequency calculated at the magnetic axis. 


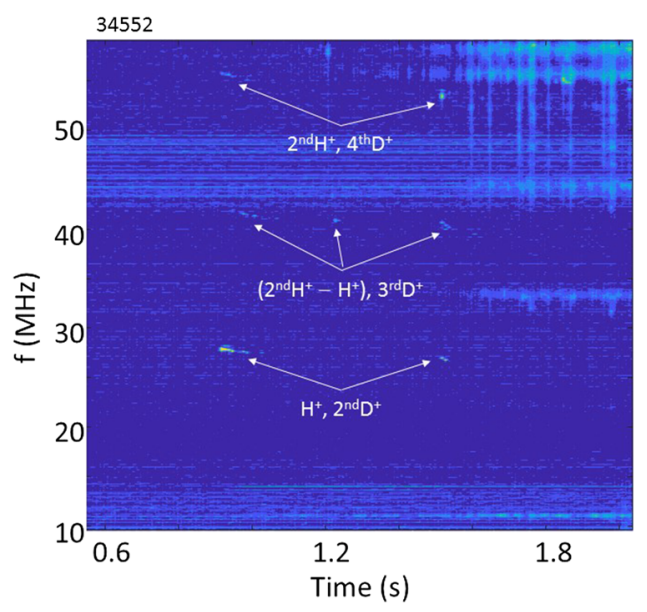

FIG. 4. ICE frequency spectrum for the discharge shown in Figs. 3(a)-3(d).

maintaining the total injected power constant) [Fig. 3(h)]. Interestingly, the high field side (HFS) probes also observe this core ICE, albeit at a reduced amplitude compared to the low field side (LFS) probes [Figs. 3(c) and 3(g)]. This suggests that the reabsorption of the excited wave by the bulk plasma is not complete in either radial direction as ICE travels radially from the source to the low and the high field sides.

The $1 \mathrm{~ms}$ acquisition time window of the fast ICE diagnostic allows us to measure ICE features with $1 \mathrm{kHz}$ resolution in the frequency domain. We often observe that core ICE consists of multiple closely spaced frequency peaks (Fig. 5). The dominant splitting usually consists of 2-4 peaks (but can be more) that are $\sim 100-200 \mathrm{kHz}$ apart [Figs. 5(a) and 5(c)]. However, a fine scale splitting of individual peaks $(\sim 10 \mathrm{kHz}$ apart $)$ can also be seen [Fig. 5(c)]. This fine splitting is more apparent when examining the phase output of the slow ICE diagnostic measured between two probes $\sim 2.4 \mathrm{~cm}$ apart: the phase value is not constant but shows periodic sweeps (every $\sim 0.1 \mathrm{~ms}$ ) [Fig. 5(d)]. These phase sweeps are consistent with a beatwave formed by ICE waves that are $\sim 10 \mathrm{kHz}$ apart. Thus the phase measurement confirms that the observed fine frequency splitting is a feature of the emission. Independent observations of frequency splitting have also been made in NBI heated discharges on the TUMAN-3M tokamak. ${ }^{13}$

An important issue is the possible fast ion driver of the observed core ICE. The fundamental minority hydrogen and second harmonic deuterium cyclotron resonances coincide (Fig. 6), and both of these fast ion species are present in deuterium plasmas heated with deuterium NBI: fast hydrogen ions are produced as a result of the D-D nuclear fusion reaction and fast deuterium ions are directly injected by NBI. The fast fusion protons, once born in the core of ASDEX Upgrade discharges, are not all promptly lost to the wall. Two independent fast ion (full orbit) tracking codes, Orb and Dimon, have been used to determine the region of velocity space of fast fusion protons born at the magnetic axis corresponding to confined orbits. The codes show that protons born with pitch values $\left(\equiv \mathrm{V}_{\|} / \mathrm{V}_{\text {Tot }}\right.$, where $V_{\|}$is the fast ion velocity component parallel to the local magnetic field and $\mathrm{V}_{\text {Tot }}$ is its total velocity) greater than 0.45 (co-current) and less than -0.72 (counter-current) remain confined (Fig. 6) and can, in principle, drive the observed emission. The thermalized hydrogen fraction is typically $5 \%$ in AUG $\mathrm{D}^{+}$ discharges, sufficient to ensure the existence of the hydrogen minority-wave resonance in the plasma core. However, ICRF power was not applied during any of the time intervals considered here, and so fusion reactions are the only source of hydrogen ions capable of driving ICE. The Alfvèn velocity in the core plasma is $\sim 5-6 \times 10^{6} \mathrm{~m} \mathrm{~s}^{-1}$, well below the fast fusion proton birth velocity $\left(2.4 \times 10^{7} \mathrm{~m} \mathrm{~s}^{-1}\right)$ but a factor of two above the injected deuterium beam ion birth velocity $\left(2.4 \times 10^{6} \mathrm{~m} \mathrm{~s}^{-1}\right)$. This suggests that the core ICE driver is likely to be the fusion-born protons and not the beam ions since it is driven more readily when the fast ions are super-Alfvènic. ${ }^{14}$ Indeed fusion protons were identified as the driver of ICE in the KSTAR discharges considered in Ref. 15, although in this case the emission frequencies place the origin of the emission at the low field side plasma edge rather than at the magnetic axis. However, to unambiguously resolve the nature of the core ICE driver (fast proton vs fast deuteron), one needs to calculate the particle-wave coupling strength for the two fast ion species using a suitable numerical scheme. ${ }^{16}$
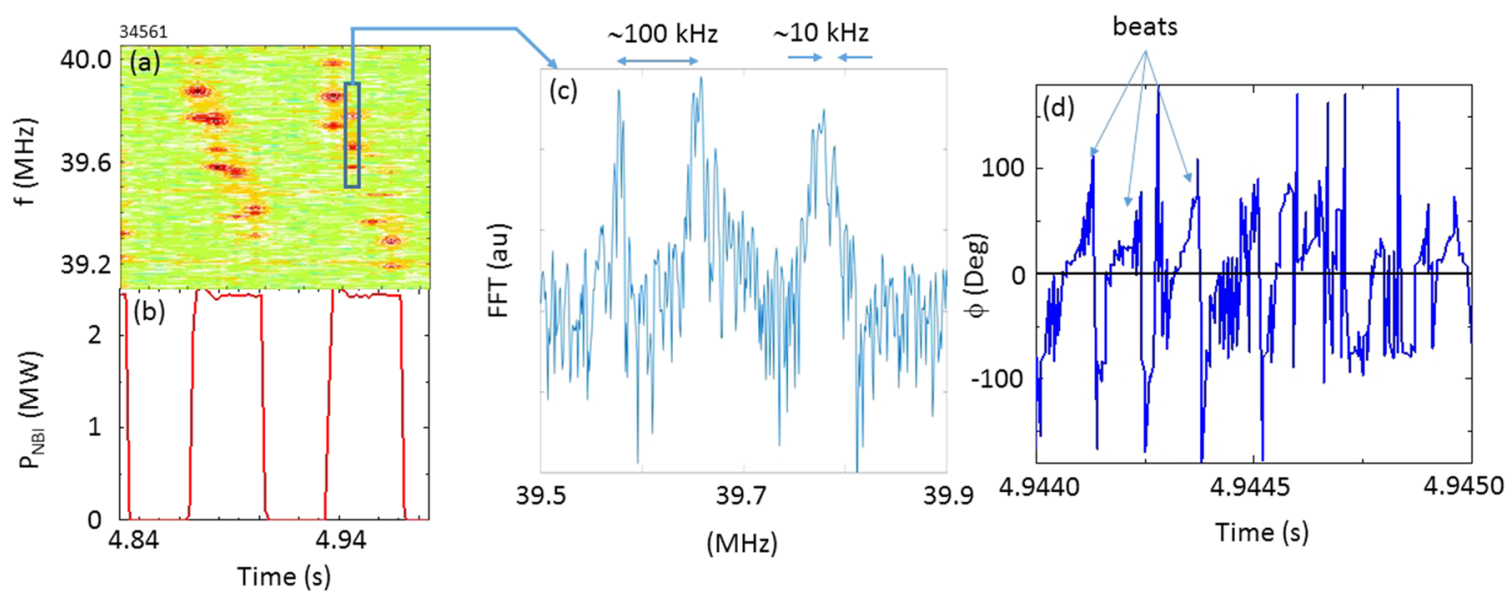

FIG. 5. Measured ICE spectra (a) during NBI pulses (b) in discharge at $\mathrm{B}_{\mathrm{T}}=-2.62 \mathrm{~T}$. The effect of frequency splitting at levels of $\sim 100 \mathrm{kHz}$ and $\sim 10 \mathrm{kHz}$ (c) and the confirmation of the fine $\sim 10 \mathrm{kHz}$ frequency splitting via a phase measurement (d). 


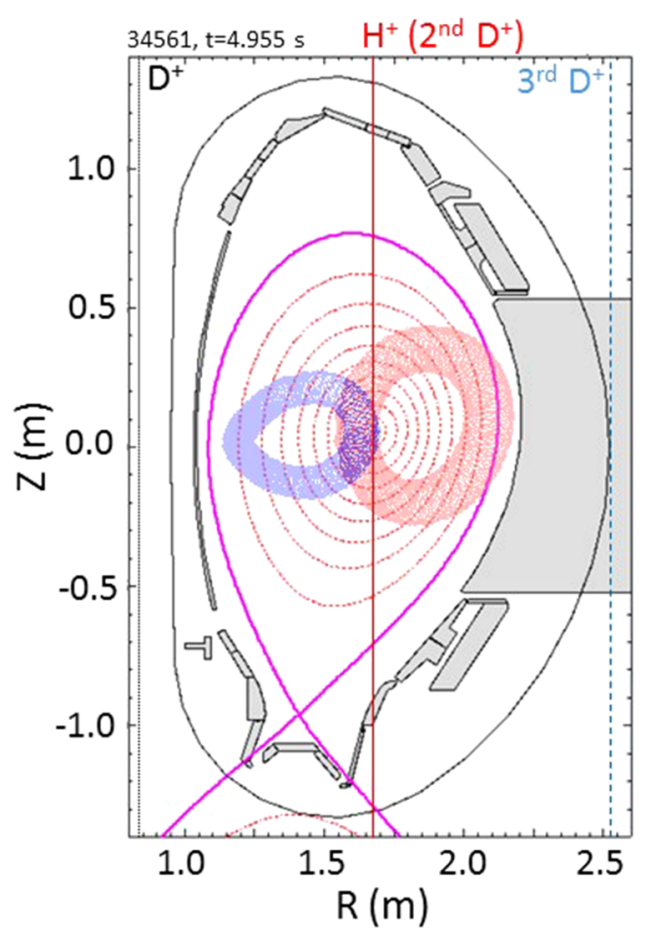

FIG. 6. Frequency matched radial positions of the fundamental deuterium (dotted black line), the fundamental hydrogen (solid red line), and the third harmonic deuterium (dashed blue line) cyclotron frequencies for discharge shown in Fig. 5. The two shown orbits correspond to barely confined fusion proton orbits. Both orbits originate at the magnetic axis.

\section{CONCLUSIONS}

The ICE diagnostic on ASDEX Upgrade has been upgraded with a fast 2-channel, 14 bit resolution digitizer, which makes it possible to study ICE in greater detail than before. While the classic ICE features of emission from the low field side plasma edge often occur in AUG plasmas (Fig. 2), we also observe emission with frequencies that are consistent with a magnetic axis location, with either fusion-born protons or deuterium beam ions driving this emission (Figs. 3 and 4). The frequencies of this core ICE range from $\sim 27 \mathrm{MHz}$ at $\mathrm{B}_{\mathrm{T}}=-1.79 \mathrm{~T}$ to $\sim 40 \mathrm{MHz}$ at $\mathrm{B}_{\mathrm{T}}=-2.62 \mathrm{~T}$, matching the fundamental hydrogen and the second harmonic deuterium cyclotron frequencies at the magnetic axis location [Figs. 3(d) and 3(h)]. If the magnetic axis undergoes a radial shift during core ICE, the measured ICE frequency change tracks the calculated on-axis value [Fig. 3(d)]. The instability is usually brief ( $\sim 100 \mathrm{~ms}$ long) and is most common during the NBI startup phase [Figs. 3(a)-3(d)]. However, core ICE can also be excited during steady-state conditions and can persist for more than
$1 \mathrm{~s}$ [Figs. 3(e)-3(h)]. The high resolution of the new fast ICE diagnostic reveals fine-scale structures in core ICE: two levels of frequency splitting are present at characteristic values of $\sim 100 \mathrm{kHz}$ and $\sim 10 \mathrm{kHz}$ (Fig. 5). In general, core ICE observed on ASDEX Upgrade is consistent with the theoretical expectations by Cordey et al. ${ }^{10}$ —an instability which is driven by fast fusion born ions in the plasma core. These measurements strengthen the case of an ICE diagnostic as a non-perturbing method of observing centrally born fusion alpha particles in deuterium-tritium burning plasma devices such as ITER or DEMO. ${ }^{1}$

\section{ACKNOWLEDGMENTS}

This work has been carried out within the framework of the EUROfusion Consortium and has received funding from the Euratom research and training programme 20142018 under Grant Agreement No. 633053. The views and opinions expressed herein do not necessarily reflect those of the European Commission. The authors also acknowledge the contribution of Rodolphe D'Inca in the conceptual design and assembly of the fast ICE diagnostic on ASDEX Upgrade. Fruitful discussions with Roberto Bilato on the subject of ICE are also acknowledged.

${ }^{1}$ K. G. McClements et al., Nucl. Fusion 55, 043013 (2015).

${ }^{2}$ R. D'Inca, M. Garcia-Munoz, G. Tardini, J.-M. Noterdaeme, and ASDEX Upgrade Team, in Proceedings of the 38th EPS Conference on Plasma Physics, 2011.

${ }^{3}$ G. A. Cottrell et al., Nucl. Fusion 33, 1365 (1993).

${ }^{4}$ K. G. McClements, R. O. Dendy, C. N. Lashmore-Davies, G. A. Cottrell, S. Cauffman, and R. Majeski, Phys. Plasmas 3, 543 (1996).

${ }^{5}$ W. W. Heidbrink et al., Plasma Phys. Controlled Fusion 53, 085028 (2011).

${ }^{6}$ S. G. Thatipamula, G. S. Yun, J. Leem, H. K. Park, K. W. Kim, T. Akiyama, and S. G. Lee, Plasma Phys. Controlled Fusion 58, 065003 (2016).

${ }^{7}$ M. Ichimura et al., Nucl. Fusion 48, 035012 (2008).

${ }^{8}$ K. Saito et al., Plasma Sci. Technol. 15, 209 (2013).

${ }^{9}$ R. O. Dendy, C. N. Lashmore-Davies, K. G. McClements, and G. A. Cottrell, Phys. Plasmas 1, 1918 (1994).

${ }^{10}$ J. G. Cordey, R. J. Goldston, and D. R. Mikkelsen, Nucl. Fusion 21, 581 (1981).

${ }^{11}$ R. Ochoukov, V. Bobkov, H. Faugel, H. Fünfgelder, J.-M. Noterdaeme, and ASDEX Upgrade Team, Rev. Sci. Instrum. 86, 115112 (2015).

${ }^{12} \mathrm{R}$. Ochoukov et al., EPJ Web Conf. 157, 03038 (2017).

${ }^{13}$ L. G. Askinazi, A. A. Belokurov, D. B. Gin, V. A. Kornev, S. V. Lebedev, A. E. Shevelev, A. S. Tukachinsky, and N. A. Zhubr, Nucl. Fusion 58, 082003 (2018).

${ }^{14}$ R. O. Dendy, C. N. Lashmore-Davies, and K. F. Kam, Phys. Fluids B 4, 12 (1992).

${ }^{15}$ B. Chapman, R. O. Dendy, K. G. McClements, S. C. Chapman, G. S. Yun, S. G. Thatipamula, and M. H. Kim, Nucl. Fusion 57, 124004 (2017).

${ }^{16}$ L. Carbajal, R. O. Dendy, S. C. Chapman, and J. W. S. Cook, Phys. Plasmas 21, 012106 (2014). 